\title{
Sexual Conflict and Sperm Competition
}

\author{
Dominic A. Edward ${ }^{1}$, Paula Stockley ${ }^{1}$, and David J. Hosken ${ }^{2}$ \\ ${ }^{1}$ Mammalian Behaviour and Evolution Group, Institute of Integrative Biology, University of Liverpool, \\ Leahurst Campus, Neston CH64 7TE, United Kingdom \\ ${ }^{2}$ Centre for Ecology and Conservation, University of Exeter, Cornwall Campus, Penryn, Cornwall \\ TR10 9FE, United Kingdom \\ Correspondence: D.J.Hosken@exeter.ac.uk
}

Traits that increase a male's fertilization success during sperm competition can be harmful to females and therefore represent a source of sexual conflict. In this review, we consider the variety of male adaptations to sperm competition (MASC) that may give rise to sexual conflict-including mate guarding, prolonged copulations, the transfer of large numbers of sperm, and the manipulation of females through nonsperm components of the ejaculate. We then reflect on the fitness economics influencing the escalation of these sexual conflicts, considering the likelihood of females evolving traits to offset the negative effects of MASC when compared with the strong selection on males that lead to MASC. We conclude by discussing the potential evolutionary outcomes of sexual conflict arising from MASC, including the opportunities for females to mitigate conflict costs and the prospects for conflict resolution.

\begin{abstract}
$M$ ale mate competition can lead to sexual conflict because male traits that increase the chances of securing a mate can reduce female fitness. For example, intense male-male competition for females in yellow dungflies can lead to females drowning in dung (Parker 1970a), or the large mandibles used to win male-male competition in Gnathocerus flour beetles reduce female fitness. This occurs via a chain of intra- and intersexual genetic correlations that results in female body morphology deviating from a fitness-optimizing feminine shape (Harano et al. 2010). Male-male competition can also continue after mating in the form of sperm competition, which arises whenever the ejaculates of two or more males are in direct competition to fertilize the same set of ova (Par-
\end{abstract}

ker 1970b, 1998). Sperm competition will select for male traits that increase a male's fertilization success, yet these traits can also be harmful to females and therefore represent a source of sexual conflict, even in situations in which females initiate polyandry (Stockley 1997).

In this article, we begin by briefly reviewing some of the many male adaptations to sperm competition (MASC) and how these can give rise to sexual conflict. We then go on to discuss factors that may govern the extent of sexual conflict arising from MASC. In particular, we reflect on the importance of the relative costs and benefits of these traits to males and females, as understanding the fitness economics of sexual conflict is central to determining the potential evolutionary trajectories of MASC. We con-

Editors: William R. Rice and Sergey Gavrilets

Additional Perspectives on The Genetics and Biology of Sexual Conflict available at www.cshperspectives.org

Copyright (C) 2015 Cold Spring Harbor Laboratory Press; all rights reserved; doi: 101101/cshperspect.a017707 Cite this article as Cold Spring Harb Perspect Biol 2015;7:a017707 
D.A. Edward et al.

clude by discussing avenues through which females could mitigate costs and the prospects for conflict resolution.

\section{CAUSES OF SEXUAL CONFLICT}

If the expression of a trait increases the fitness of one sex while reducing fitness of the other, sexual conflict occurs. In principle, it is straightforward to decide whether there is sexual conflict over a trait by simply asking, would trait values change if expression levels were completely controlled by only one sex. For example, if female influence on copulation duration or sperm storage is removed, does copulation duration increase/decrease or do sperm storage patterns differ (e.g., Hellriegel and Bernasconi 2000)?

Within this general framework there exists a wide variety of MASC that can lead to sexual conflict. Male adaptations include mating behaviors, such as mate guarding and extended or repeated copulation; alterations to ejaculate size or composition, including sperm number; and the use of copulatory plugs and strategic allocation of mating effort, including male mate choice (Parker 1970b, 1998; Edward and Chapman 2011). Some MASC may reduce either the risk or intensity of sperm competition (Parker 1998). For example, mate guarding or mating plugs made from ejaculate components (e.g., Fenton 1984) or detached male genitals (e.g., Nessler et al. 2007; Kuntner et al. 2009) can prevent or delay female remating, and a similar function has been suggested for copulatory stimulation (Stockley 2002). Indeed, any male trait that reduces female remating rates may have evolved, in part at least, through selection arising from the risk of sperm competition. Other MASC, rather than reducing competition, can increase male fitness when sperm directly compete. For example, adaptations that function in physically removing or debilitating rival sperm (e.g., Cordoba-Aguilar et al. 2003). MASC can also be classified as benefiting either the earlier mating male over subsequent competitors (i.e., defensive traits), or benefiting later mating males when a female has previously mated (i.e., offensive traits). Such adaptations can each increase male fertilization success when sperm competition does arise and can result in sexual conflict.

The majority of examples of sexual conflict arising from MASC reviewed here relate to interlocus conflict (i.e., conflicting alleles are present at different loci in males and females). For example, a sexual conflict over mating duration may be determined by male persistence traits that are expressed at one locus and female resistance traits expressed at a different locus. However, MASC can potentially also give rise to intralocus sexual conflict (i.e., when an allele at a single locus has contrasting fitness effects when expressed in either males or females). Although there is currently limited direct evidence of this (Lewis et al. 2008), in Callosobruchus maculatus, males that are more harmful to their mates, which may increase male fitness, sire daughters that are more susceptible to harm (Gay et al. 2011).

\section{Male Mating Behavior}

\section{Mate Guarding}

Males can prevent or reduce the risk of sperm competition by guarding their mates. Mate guarding is found in many taxa and is manifest as either extended physical contact (including extended copulation-see below) or remaining close to recent partners so that copulations with other males can be delayed or prevented.

The prolonged association between males and females that occurs with mate guarding must generate opportunity costs for both sexes, as the time involved might otherwise be spent on other fitness-related activities such as foraging (e.g., Westneat 1994; Komdeur 2001). Mate guarding may be particularly costly for females if guarding males have low fertility, as reported for cockroaches, Nauphoeta cinerea, in which males that have become sperm depleted will continue to enforce female monogamy (Montrose et al. 2004). In some cases, mate guarding can also limit a female's ability to exercise cryptic mate choice, for example by delaying sperm ejection (Helfenstein et al. 2003), or may limit other aspects of behavior such as choice of oviposition sites (Smith et al. 2002). However, 
mate guarding can also be beneficial for females if it reduces sexual harassment. Indeed, female blackbirds, Turdus merula, appear to actively prolong sexual activity to induce mate guarding, as they benefit from reduced harassment by other males and also receive greater paternal care of offspring from their guarders as a result (Wysocki and Halupka 2004).

Nonetheless, if mate guarding is costly for females, selection will favor female traits that reduce guarding duration. For example, females may struggle to escape from males, as in sepsid flies (Parker 1972; Hosken et al. 2003). However, this can generate additional costs for females (e.g., physical injury) and the extent of female resistance will depend on the relative costs of guarding and resistance. Where mate guarding is important to male reproductive success, as it is in sepsids (guarding males only mate after egg laying) (Parker 1972; Hosken et al. 2003), then males should respond to female resistance, potentially leading to coevolutionary arms races between male guarding and female resistance strategies. An excellent example of this is the correlated evolution of male grasping and female antigrasping structures found across 15 species of gerrid water striders (Arnqvist and Rowe 2002).

\section{Extended or Repeated Copulations}

Another MASC is to prolong mating, either by extending copula duration, pre- or postejaculation (e.g., Cordoba-Aguilar et al. 2009), or copulating repeatedly with the same female (e.g., Laird et al. 2004; Stockley and Preston 2004; Preston and Stockley 2006). There are many examples of males strategically altering copulation to benefit either from the guarding effect of this behavior (see above) or from transferring larger ejaculates to potentially achieve greater fertilization success (e.g., Wedell 1998; Martin and Hosken 2002).

Extended or repeated copulations typically allow males to pass more sperm or other nonsperm ejaculate components to their mates (see the section Ejaculate Variation below) and can also allow males to displace the ejaculates of previous rivals (Parker and Simmons 2000).
This is clearly beneficial in situations in which sperm number is the primary determinant of fertilization success during sperm competition (Parker 1984, 1998). Extended or repeated copulations may also give males greater opportunity to assess female mating status and to strategically adjust mating effort accordingly (see the section Strategic Allocation of Male Mating Effort below). Additionally, it has been suggested that males may repeatedly attempt to mate with the same female to assess receptivity to further copulations (Sato and Kohama 2007).

Prolonged copulations are likely to generate costs of mate guarding for females because the time might otherwise be spent on other activities. In addition, prolonged and repeated copulations may increase the risk of physical injury or disease transmission associated with mating (Hosken et al. 2003). If increased copulation duration or frequency is costly for females, then selection will favor traits that reduce these costs. For example, females may struggle to terminate copulation sooner, although males extend copulation beyond the female optima (Mazzi et al. 2009) and may even control kicking duration (Wilson and Tomkins 2014). Where males have evolved to physically prevent females escaping, struggles such as these may lead to physical injury of females (e.g., Hotzy and Arnqvist 2009; Johns et al. 2009). Nevertheless, an assessment of the level of sexual conflict arising from prolonged copulations should also consider potential benefits to females. Costs may be mitigated if females benefit from, for example, an increased ability to assess male quality or reduced costs of harassment from other males (e.g., Eberhard 1996). Females may also directly benefit from the receipt of more sperm or nuptial gifts (Arnqvist and Nilsson 2000).

\section{Ejaculate Variation}

\section{Sperm Number, Quality, and Morphology}

When sperm compete numerically, a male may increase his fertilization success simply by ejaculating more sperm (Parker 1998). This response to sperm competition risk has been shown repeatedly (e.g., Gage 1991; Simmons 
D.A. Edward et al.

et al. 1993; Wedell 1998; Martin and Hosken 2002). Males can increase sperm number by increasing copulation duration, ejaculating repeatedly with the same female (see section above) or by increasing sperm transfer rates. This male strategy has many potential costs to females, including reducing female control of paternity and increasing the risk of polyspermy. This could explain why the female reproductive tract is typically hostile to sperm (Birkhead et al. 1993) and females may eject unwanted sperm (e.g., Manier et al. 2010; Dean et al. 2011b). Alternatively, when the intensity of sperm competition is high, or anticipated payoffs of mating are relatively low, males may benefit from transferring fewer sperm (Parker et al. 1996), or searching for alternative mating opportunities (Schwagmeyer and Parker 1990). In rainbow darters, Etheostoma caeruleum, larger males often forego mating opportunities in which there is a high intensity of sperm competition, instead conserving resources in anticipation of less competitive future matings (Fuller 1998). This may be costly for females if they benefit from polyandry or from mating with larger males.

In addition to varying sperm numbers, adjusting sperm quality may also be a MASC (Ball and Parker 1996). For example, sperm competition risk can influence sperm morphology and performance (Gage and Morrow 2003). However, selection for increased sperm swimming speed/fertilization efficiency is thought to be a key factor in the incidence and impact of polyspermy (Snook et al. 2011). So although highly competitive sperm may be advantageous for males, they may result in ova loss for females. If so, increased sperm competition, and associated MASC, may select for tolerance to polyspermy, which could explain why in some taxa, such as birds, polyspermy does not result in fertilization failure (Snook et al. 2011).

Greater investment in sperm number or sperm quality will ultimately trade off against other traits (Parker 1998). Sperm number and quality may also trade off against each other, in which case selection to increase either trait will depend on the mechanism of sperm competition (Immler et al. 2011). Alternatively, both sperm number and sperm quality may in- crease in response to sperm competition (Locatello et al. 2007) potentially forcing a trade-off with nonejaculate traits. For example, ejaculate quality may trade off with attractiveness (Evans 2010; Rowe et al. 2010) or immune function (Simmons 2012), and testes size has been shown to trade off with traits such as flight capability (Saglam et al. 2008) and weaponry (Simmons and Emlen 2006). It is therefore possible that increased investment in ejaculates could trade off with traits that directly enhance female fitness, such as nuptial gift size or provision of parental care (e.g., Simmons et al. 1993). For example, male secondary sexual traits can trade off with paternal care provision (Smith 1995) and such trade-offs could be mediated by testosterone production (Wingfield et al. 1990; Mascaro et al. 2013).

Greater investment in each ejaculate, without a concomitant increase in sperm production, could contribute to female sperm limitation (Wedell et al. 2002). For example, in two heteropterans with different mating systems, male investment in spermatogenesis differs and this has profound effects on female fitness (Franco et al. 2011). In the monoandrous Macrolophus pygmaeus, females receive enough sperm to fertilize the majority of their ova. In contrast, in the polyandrous Nesidiocoris tenuis, females run out of sperm soon after mating, and so must readily accept copulations and spend longer in copula to maintain fertility. Ultimately, if the cost of producing a competitive ejaculate is sufficiently high, male mating rates may be reduced. This could influence the direction of sexual selection as female-female competition for mates increases (Lorch 2002; Wedell et al. 2002).

In many taxa males produce more than one sperm type, but usually only one sperm class are fertilizing sperm (eusperm) (Pitnick et al. 2009). Nonetheless, the nonfertilizing (apyrene or para-) sperm can affect the outcome of sperm competition and their receipt can be costly for females. In Drosophila pseudoobscura, for example, the survival of eusperm within the female reproductive tract is highest when greater numbers of apyrene sperm are also inseminated (Holman and Snook 2008). Additionally, in the green-veined white butterfly, Pieris napi, 
nonfertile sperm fill the female sperm storage organ, reducing female receptivity to further copulations, which is clearly in male interests (Wedell 2001). The receipt of nonfertile sperm is costly for females as it reduces fertility, which will be compounded if remating is delayed. The precise function of most apyrene sperm is unclear, but larger apyrene sperm may fill female sperm storage organs or block female genital tracts, excluding sperm from other males (see the section Copulatory Plugs below). Again, this is likely to be beneficial to males but costly to females if polyandry is in female interests.

\section{Nonsperm Ejaculate Substances}

In addition to sperm, ejaculates can contain a wide variety of substances that influence sperm competitiveness. These have been particularly well studied in Drosophila melanogaster (e.g., Wolfner 2002; Chapman 2008), although they are taxonomically widespread (Perry et al. 2013). Seminal peptides found in the ejaculate of male D. melanogaster influence many aspects of female physiology and behavior, including female remating rate, egg production rate, and sperm storage. By manipulating these female traits, males increase their fertilization success. Furthermore, it has been shown that male $D$. melanogaster strategically adjust allocation of seminal peptides in accordance with female mating status and the perceived risk of sperm competition (Wigby et al. 2009; Fedorka et al. 2011; Sirot et al. 2011) as predicted by theory (Hodgson and Hosken 2006). However, male manipulation comes at a cost to females, as seminal fluid proteins reduce female longevity (Chapman et al. 1995) and alter egg production schedules to reduce female lifetime reproductive success (Wigby and Chapman 2005). Furthermore, if female evolutionary responses to male manipulation are halted, males evolve to be even more manipulative and females pay even greater costs (Rice 1996).

There is evidence that females evolve to mitigate the costs of nonsperm ejaculate components. For example, resistance to seminal fluid proteins evolves when female $D$. melanogaster are subjected to higher mating rates (Wigby and Chapman 2004). Studies have also begun to identify candidate genes expressed in the female that interact with male seminal proteins (Swanson et al. 2004; Chow et al. 2010). Male adzuki bean beetles (Callosobruchus chinensis), for example, transfer substances to females during mating that reduce female receptivity. Female beetles from strains in which the potency of these substances is greater were found to have evolved greater resilience to their effects, suggestive of coevolution between male manipulation and female resistance (Yamane and Miyatake 2012).

Nonsperm ejaculate substances can also interfere with the female immune response (Morrow and Innocenti 2012). These traits may have evolved because sperm are foreign bodies and females often show an immune response after insemination that may indirectly, or directly, target sperm. In the cricket, Allonemobius socius, seminal components interrupt phenoloxidase activity, a key pathway in insect immunity, thus compromising female immune function (Fedorka and Zuk 2005). Although this may benefit males by ensuring that a greater number of their sperm survive to compete, it may also leave females more vulnerable to disease.

\section{Copulatory Plugs}

Another MASC is to block the female genital tract with a copulatory plug. Copulatory plugs are found in many taxa (e.g., Lung and Wolfner 2001; Dixson and Anderson 2002; Moreira and Birkhead 2004; Ramm et al. 2005) and can prevent or delay female remating (e.g., Takami et al. 2008) or facilitate sperm transport within the female reproductive tract (e.g., Dean 2013). Copulatory plugs are often derived from the nonsperm portion of the ejaculate, although the male genitalia themselves can also act as plugs (e.g., Herberstein et al. 2012). Plugs can be costly to females if they prevent remating but they can also prevent females from using or storing sperm efficiently. There is indirect evidence that females find copulatory plugs costly to some extent as they are often removed shortly after copulation (e.g., Takami et al. 2008) and females can produce proteases that degrade the 
D.A. Edward et al.

structure of the plug (Dean et al. 2011a). This has the potential to generate antagonistic coevolution between males and females, with males selected to improve plug efficacy and females to remove or degrade them. There is evidence for this in rodents, in which a number of different ejaculatory proteins form the plug along with a variety of protease inhibitors that disrupt the action of female degradation enzymes (Dean et al. 2011a). A further female-borne cost of plugs can arise if males attempt to mate with "plugged" females (e.g., Moreira and Birkhead 2004). Females could incur physical harm, particularly if males have evolved traits such as penile spines to assist in plug removal.

Again, however, an assessment of the level of sexual conflict arising from copulatory plugs should also consider potential benefits to females. Plugs can be large enough to ensure that some of the plugging cost can be offset if the female is able to consume the plug on removal or absorb nutrients from the plug as it is degraded. A plug may also be beneficial if this increases fertility (Timmermeyer et al. 2010; Dean 2013) or protects the female from male harassment (e.g., Kuntner et al. 2012).

\section{Strategic Allocation of Male Mating Effort}

Another way for males to maximize fitness returns when faced with the risk of sperm competition is to either not mate with, or allocate fewer resources to, already mated females (e.g., Simmons et al. 2003; Friberg 2006). Saved resources might then be allocated elsewhere. It is now increasingly accepted that males can be choosy, particularly if, in the face of intense sperm competition, males are under strong selection to produce larger or more complex ejaculates that may limit mating rates (Lorch 2002; Wedell et al. 2002; Edward and Chapman 2011). If the energy required to mate is high, the prospects of securing paternity are low and if other females are likely to be available, then males might be better off searching for alternative mates (Schwagmeyer and Parker 1990). However, it should be remembered that strategic allocation of mating effort will only benefit males if alternative, more economical mating opportunities are available to which saved resources can be reallocated (e.g., Fuller 1998; Barry and Kokko 2010).

If males allocate fewer resources (i.e., fewer sperm or smaller ejaculates), or are less willing to mate with nonvirgin females, this could reduce female fertility. Females could also incur costs of reduced mate choice, for example by not being able to "trade up" to a better mate, or be unable to secure additional fitness-enhancing nuptial gifts. Female adaptations to avoid costs of strategic allocation of male mating effort might include disguising mating status or perhaps even signaling competitively to attract males (e.g., Clutton-Brock 2009; Stockley et al. 2013). Female signals that indicate greater fecundity might convince a male that the potential rewards of mating outweigh potential costs of sperm competition (e.g., LeBas et al. 2003).

\section{THE EXTENT OF SEXUAL CONFLICT}

\section{Costs and Benefits to Males}

MASC are often costly for males and thus may limit other reproductive investment. For example, increasing ejaculate production or producing larger copulatory plugs may require significant energetic investment and trade-off against other fitness components (Hosken 2001). Similarly, prolonged guarding or copulatory behaviors can be costly in terms of both time and energy. This can potentially result in trade-offs such as that between mate guarding and territory size in male stitchbirds, Notiomystis cincta (Low 2005). The costs of MASC are further evidenced by examples of strategic ejaculate allocation and variation in male mating behavior and mate guarding behavior according to perceived levels of sperm competition (Komdeur 2001; Wedell et al. 2002; Bretman et al. 2009). If MASC were not costly there would be little or no selection for plasticity in their expression. Costs may also be more obvious than this. As an extreme example, the ability of males to remate is limited when genitals are broken off during mating to form a copulatory plug (e.g., Nessler et al. 2009).

The costs of expressing MASC will ultimately impose a limit on the evolution of these traits and hence the potential to inflict harm on fe- 
males could be self-limiting. However, the harm inflicted on females may still be significant as male costs are often outweighed by very strong selection for these characters. If the risk or intensity of sperm competition is high, selection can thus still favor the expression of MASC that are very costly to males. For example, in the orbweb spider, Argiope lobata, males break off part of their genitalia to form a copulatory plug that increases their share of paternity if the female should remate. This occurs despite the very significant cost of a reduction in the male's ability to remate, and an increased risk of sexual cannibalism (Nessler et al. 2009). Nevertheless, the fitness benefits of depositing the plug are sufficient to outweigh even these extreme costs, which is in part owing to the paucity of future mating opportunities (Nessler et al. 2009). This shows that the strength of selection on males through sperm competition can be sufficient to select for costly characters, which in turn can generate sexual conflict.

\section{Costs and Benefits to Females}

Although MASC can be under strong selection, corresponding selection in females to resist them may be weaker as MASC are unlikely to cause a complete loss of female fitness. Basically, the variance in male reproductive success is typically higher than that in females. Thus in general we might predict, at least initially, greater selection for males to express MASC than for females to evolve resistance to them. The balance of selection may therefore tend to favor the evolution of MASC, with weaker selection for female resistance to them. Consequently, females probably suffer a greater conflict load (i.e., females may be further from their fitness optima as a result of sexual conflict). However, this prediction is complicated by the costs of female resistance (see the section Mitigation and Resolution of Sexual Conflict below).

Finally, there are potential female benefits from MASC. An assessment of these benefits is important not only for accurately determining the conflict load, but also the precise trait, or aspect of a trait, over which there may be a sexual conflict. For example, a copulatory plug can improve fertilization success and thus benefit both sexes (e.g., Timmermeyer et al. 2010; Dean 2013). Consideration should then be given to whether there is conflict over plug formation per se, or only over the optimal size or consistency of the plug.

It may also be important to consider how fitness costs of MASC are measured. Male manipulation of female egg production may function as a MASC as it will benefit males if more fertilized eggs are produced before females remate. This manipulation can have a detrimental effect on female lifespan and/or lifetime reproductive success (Chapman et al. 1995; Wigby and Chapman 2005). However, the production of more offspring at a young age will also contribute to an individual's intrinsic rate of offspring production. This can enhance female fitness, particularly if other females in a population are also being stimulated to produce more offspring so that population size is increasing (Edward et al. 2011). Thus, female fitness may, under certain conditions, be increased despite a reduction in overall lifetime reproductive success. This highlights the importance of not only considering the potential fitness benefits of MASC to females but also greater consideration of the way that fitness is measured.

In summary, to understand the precise nature and extent of sexual conflict arising from MASC it is important to understand the costs and benefits of conflict in both sexes. The effects of MASC can be complex, and although there is often an obvious cost to females, potential benefits of these traits can easily be overlooked. A key challenge for future research is a more complete consideration of the fitness economics of sexual conflict and improved measurement of the costs involved.

\section{MITIGATION AND RESOLUTION OF SEXUAL CONFLICT}

Although it is clear that MASC can give rise to sexual conflict, the evolutionary trajectories of such conflicts are less clear. Although there is potential for selection arising from MASC to favor female traits that directly counter them, conflict need not lead to selection. Outcomes 
D.A. Edward et al.

depend in part on how costly it is to resist MASC and the strength of selection imposed on females. An important factor here is that despite strong selection acting on males, female resistance traits could be relatively cheap to produce and express (Parker 1979, 1984). For example, although a copulatory plug may be very costly to produce, it could be relatively easy for a female to remove. This kind of asymmetry could tilt evolutionary outcomes of these conflicts in favor of females, despite stronger selection acting on males. However, although female cost-avoiding responses to one MASC could potentially resolve a specific conflict, this could have the potential to select for an alternative MASC, thus kick-starting new rounds of sexually antagonistic coevolution.

Sperm competition is intimately related to polyandry, and because of this, the causes and patterns of polyandry may also be particularly important in determining the nature of sexual conflict that results. It is clear that females can benefit from polyandry (Arnqvist and Nilsson 2000; Fedorka and Mousseau 2002; Slatyer et al. 2012), yet mating too often can be costly (Arnqvist and Nilsson 2000). Hence, the net benefits or costs of polyandry should influence specific sexual conflicts arising from MASC.

If actual rates of polyandry are greater than the female optima, selection will favor female traits that reduce mating rates. Selection for reduced rates of polyandry should in turn be expected to reduce levels of sperm competition and thus potentially also reduce the costs arising from MASC_-although it could spark other sexual conflicts if males are moved below their optimal mating rates. Alternatively, if rates of polyandry are below the female optima, females will be selected to increase multiple mating. In this case females can generate a conflict load from MASC via selection for polyandry. As long as fitness benefits of polyandry exceed subsequent fitness costs of MASC we would expect selection for rates of polyandry to be maintained. However, it is not easy to disentangle cause and effect. Females may be seen to have higher fitness with increased mating because they have evolved to reduce costs by storing fewer sperm. That is, because sperm are so easy to acquire females do not need to store them. Thus, it is not always clear whether female multiple mating is because males transfer few sperm or females simply do not want to store them.

Additionally, as rates of polyandry are often only indirectly associated with sexual conflict arising from MASC it is not inevitable that an individual reduction in mating rates will reduce costs of this conflict. If a majority of females in a population are polyandrous and/or if MASC are relatively cheap to produce, it is likely that they will be expressed even at low risk of sperm competition. Consequently, a female trait that reduces mating rates is unlikely to confer an immediate benefit to its bearer through reduced costs of MASC. However, if males assess female mating status to determine the risk of sperm competition and adjust the expression of MASC accordingly, then an individual female with a lower rate of polyandry could benefit from a reduction in costs associated with MASC.

In summary, a resolution of sexual conflict over MASC may be reached directly or indirectly via reduced rates of polyandry. However, this will be dependent on the benefits of polyandry to females, including whether rates of polyandry are above or below optima, and whether MASC are tailored according to the immediate risk of sperm competition. Unfortunately at this point in time it is not even clear how sexual conflict generates selection generally, and not just how often MASC actually reduce female fitness. These are areas that need empirical work on a broad range of taxa to allow us to have some feel for general patterns.

\section{ACKNOWLEDGMENTS}

We are grateful to Bill Rice and Sergey Gavrilets for the opportunity to write this article. We appreciate support from National Environmental Research Council (NERC) Grant NE/ I013008/1 (P.S. and D.A.E.).

\section{REFERENCES}

Arnqvist G, Nilsson T. 2000. The evolution of polyandry: Multiple mating and female fitness in insects. Anim Behav 60: 145-164. 
Arnqvist G, Rowe L. 2002. Correlated evolution of male and female morphologies in water striders. Evolution 56: $936-947$.

Ball MA, Parker GA. 1996. Sperm competition games: External fertilization and "adaptive" infertility. J Theor Biol 180: $141-150$.

Barry KL, Kokko H. 2010. Male mate choice: Why sequential choice can make its evolution difficult. Anim Behav 80: $163-169$.

Birkhead TR, Moller AP, Sutherland WJ. 1993. Why do females make it so difficult for males to fertilize their eggs. J Theor Biol 161: 51-60.

Bretman A, Fricke C, Chapman T. 2009. Plastic responses of male Drosophila melanogaster to the level of sperm competition increase male reproductive fitness. Proc $R$ Soc Lond B 276: 1705-1711.

Chapman T. 2008. The soup in my fly: Evolution, form and function of seminal fluid proteins. PLoS Biol 6: 13791382.

Chapman T, Liddle LF, Kalb JM, Wolfner MF, Partridge L. 1995. Cost of mating in Drosophila melanogaster females is mediated by male accessory-gland products. Nature 373: $241-244$.

Chow CY, Wolfner MF, Clark AG. 2010. The genetic basis for male $\times$ female interactions underlying variation in reproductive phenotypes of Drosophila. Genetics 186: $1355-1365$.

Clutton-Brock T. 2009. Sexual selection in females. Anim Behav 77: 3-11.

Cordoba-Aguilar A, Uhia E, Rivera AC. 2003. Sperm competition in Odonata (Insecta): The evolution of female sperm storage and rivals' sperm displacement. J Zool 261: 381-398.

Cordoba-Aguilar A, Serrano-Meneses MA, Cordero-Rivera A. 2009. Copulation duration in nonterritorial odonate species lasts longer than in territorial species. Ann Entomol Soc Am 102: 694-701.

Dean MD. 2013. Genetic disruption of the copulatory plug in mice leads to severely reduced fertility. PLoS Genet 9: e1003185.

Dean MD, Findlay GD, Hoopmann MR, Wu CC, MacCoss MJ, Swanson WJ, Nachman MW. 2011 la. Identification of ejaculated proteins in the house mouse (Mus domesticus) via isotopic labeling. BMC Genomics 12: 306.

Dean R, Nakagawa S, Pizzari T. 2011b. The risk and intensity of sperm ejection in female birds. Am Nat 178: 343-354.

Dixson AF, Anderson MJ. 2002. Sexual selection, seminal coagulation and copulatory plug formation in primates. Folia Primatol 73: 63-69.

Eberhard WG. 1996. Female control: Sexual selection by cryptic female choice. Princeton University Press, Princeton.

Edward DA, Chapman T. 2011. The evolution and significance of male mate choice. Trends Ecol Evol 26: 647-654.

Edward DA, Fricke C, Gerrard DT, Chapman T. 2011. Quantifying the life-history response to increased male exposure in female Drosophila melanogaster. Evolution 65: $564-573$.

Evans JP. 2010. Quantitative genetic evidence that males trade attractiveness for ejaculate quality in guppies. Proc Biol Sci 277: 3195-3201.
Fedorka KM, Mousseau TA. 2002. Material and genetic benefits of female multiple mating and polyandry. Anim Behav 64: 361-367.

Fedorka KM, Zuk M. 2005. Sexual conflict and female immune suppression in the cricket, Allonemobious socius. J Evol Biol 18: 1515-1522.

Fedorka KM, Winterhalter WE, Ware B. 2011. Perceived sperm competition intensity influences seminal fluid protein production prior to courtship and mating. Evolution 65: 584-590.

Fenton MB. 1984. Sperm competition: The case of vespertilionid and rhinolophid bats. In Sperm competition and the evolution of animal mating systems (ed. Smith RL), pp. 573-588. Academic, Orlando, FL.

Franco K, Jauset A, Castane C. 2011. Monogamy and polygamy in two species of mirid bugs: A functional-based approach. J Insect Physiol 57: 307-315.

Friberg U. 2006. Male perception of female mating status: Its effect on copulation duration, sperm defence and female fitness. Anim Behav 72: 1259-1268.

Fuller RC. 1998. Sperm competition affects male behaviour and sperm output in the rainbow darter. Proc Biol Sci 265: 2365-2371.

Gage MJG. 1991. Risk of sperm competition directly affects ejaculate size in the Mediterranean fruit-fly. Anim Behav 42: 1036-1037.

Gage MJG, Morrow EH. 2003. Experimental evidence for the evolution of numerous, tiny sperm via sperm competition. Curr Biol 13: 754-757.

Gay L, Hosken DJ, Eady P, Vasudev R, Tregenza T. 2011. The evolution of harm-effect of sexual conflicts and population size. Evolution 65: 725-737.

Harano T, Okada K, Nakayama S, Miyatake T, Hosken DJ. 2010. Intralocus sexual conflict unresolved by sex-limited trait expression. Curr Biol 20: 2036-2039.

Helfenstein F, Wagner RH, Danchin E. 2003. Sexual conflict over sperm ejection in monogamous pairs of kittiwakes Rissa tridactyla. Behav Ecol Sociobiol 54: 370-376.

Hellriegel B, Bernasconi G. 2000. Female-mediated differential sperm storage in a fly with complex spermathecae, Scatophaga stercoraria. Anim Behav 59: 311-317.

Herberstein ME, Wignall AE, Nessler SH, Harmer AMT, Schneider JM. 2012. How effective and persistent are fragments of male genitalia as mating plugs? Behav Ecol 23: $1140-1145$.

Hodgson DJ, Hosken DJ. 2006. Sperm competition promotes the exploitation of rival ejaculates. $J$ Theor Biol 243: $230-234$.

Holman L, Snook RR. 2008. A sterile sperm caste protects brother fertile sperm from female-mediated death in Drosophila pseudoobscura. Curr Biol 18: 292-296.

Hosken DJ. 2001. Sex and death: Microevolutionary tradeoffs between reproductive and immune investment in dung flies. Curr Biol 11: R379-R380.

Hosken DJ, Martin OY, Born J, Huber F. 2003. Sexual conflict in Sepsis cynipsea: Female reluctance, fertility and mate choice. J Evol Biol 16: 485-490.

Hotzy C, Arnqvist G. 2009. Sperm competition favors harmful males in seed beetles. Curr Biol 19: 404-407. 
D.A. Edward et al.

Immler S, Pitnick S, Parker GA, Durrant KL, Lupold S Calhim S, Birkhead TR. 2011. Resolving variation in the reproductive tradeoff between sperm size and number. Proc Natl Acad Sci 108: 5325-5330.

Johns JL, Roberts JA, Clark DL, Uetz GW. 2009. Love bites: Male fang use during coercive mating in wolf spiders. Behav Ecol Sociobiol 64: 13-18.

Komdeur J. 2001. Mate guarding in the Seychelles warbler is energetically costly and adjusted to paternity risk. Proc Biol Sci 268: 2103-2111.

Kuntner M, Kralj-Fiser S, Schneider JM, Li D. 2009. Mate plugging via genital mutilation in nephilid spiders: An evolutionary hypothesis. J Zool 277: 257-266.

Kuntner M, Gregoric M, Zhang SC, Kralj-Fiser S, Li DQ. 2012. Mating plugs in polyandrous giants: Which sex produces them, when, how and why? PLoS ONE 7: e40939.

Laird G, Gwynne DT, Andrade MCB. 2004. Extreme repeated mating as a counter-adaptation to sexual conflict? Proc Biol Sci 271: S402-S404.

LeBas NR, Hockham LR, Ritchie MG. 2003. Nonlinear and correlational sexual selection on "honest" female ornamentation. Proc R Soc Lond B 270: 2159-2165.

Lewis Z, Price TAR, Wedell N. 2008. Sperm competition, immunity, selfish genes and cancer. Cell Mol Life Sci 65: 3241-3254.

Locatello L, Pilastro A, Deana R, Zarpellon A, Rasotto MB. 2007. Variation pattern of sperm quality traits in two gobies with alternative mating tactics. Funct Ecol 21: 975-981.

Lorch PD. 2002. Understanding reversals in the relative strength of sexual selection on males and females: A role for sperm competition? Am Nat 159: 645-657.

Low M. 2005. Factors influencing mate guarding and territory defence in the stitchbird (hihi) Notiomystis cincta NZ J Ecol 29: 231-242.

Lung O, Wolfner MF. 2001. Identification and characterization of the major Drosophila melanogaster mating plug protein. Insect Biochem Mol Biol 31: 543-551.

Manier MK, Belote JM, Berben KS, Novikov D, Stuart WT, Pitnick S. 2010. Resolving mechanisms of competitive fertilization success in Drosophila melanogaster. Science 328: $354-357$.

Martin OY, Hosken DJ. 2002. Strategic ejaculation in the common dung fly Sepsis cynipsea. Anim Behav 63: 541-546.

Mascaro JS, Hackett PD, Rilling JK. 2013. Testicular volume is inversely correlated with nurturing-related brain activity in human fathers. Proc Natl Acad Sci 110: $15746-$ 15751.

Mazzi D, Kesaniemi J, Hoikkala A, Klappert K. 2009. Sexual conflict over the duration of copulation in Drosophila montana: Why is longer better? BMC Evol Biol 9: 132.

Montrose VT, Harris WE, Moore PJ. 2004. Sexual conflict and cooperation under naturally occurring male enforced monogamy. J Evol Biol 17: 443-452.

Moreira PL, Birkhead TR. 2004. Copulatory plug displacement and prolonged copulation in the Iberian rock lizard (Lacerta monticola). Behav Ecol Sociobiol 56: 290-297.
Morrow EH, Innocenti P. 2012. Female postmating immune responses, immune system evolution and immunogenic males. Biol Rev Camb Philos Soc 87: 631-638.

Nessler SH, Uhl G, Schneider JM. 2007. Genital damage in the orb-web spider Argiope bruennichi (Araneae: Araneidae) increases paternity success. Behav Ecol 18: 174-181.

Nessler S, Uhl G, Schneider J. 2009. Sexual cannibalism facilitates genital damage in Argiope lobata (Araneae: Araneidae). Behav Ecol Sociobiol 63: 355-362.

Parker GA. 1970a. The reproductive behaviour and nature of sexual selection in Scatophaga stercoraria L (Diptera: Scatophagidae): 4. Epigamic recognition and competition between males for possession of females. Behaviour 37: 113.

Parker GA. 1970b. Sperm competition and its evolutionary consequences in insects. Biol Rev Camb Philos Soc 45: 525.

Parker GA. 1972. Reproductive behavior of Sepsis cynipsea (L) (Diptera: Sepsidae): 1. Preliminary analysis of reproductive strategy and its associated behavior patterns. Behaviour 41: 172 .

Parker GA. 1979. Sexual selection and sexual conflict. In Sexual selection and reproductive competition in insects (ed. Blum MS, Blum NA), pp. 123-166. Academic, New York.

Parker GA. 1984. Sperm competition and the evolution of animal mating strategies. In Sperm competition and the evolution of animal mating systems (ed. Smith RL), pp. 2-61. Academic, Orlando, FL.

Parker GA. 1998. Sperm competition and the evolution of ejaculates: Towards a theory base. In Sperm competition and sexual selection (ed. Birkhead TR, Moller AP), pp. 3-54. Academic, Orlando, FL.

Parker GA, Simmons LW. 2000. Optimal copula duration in yellow dung flies: Ejaculatory duct dimensions and sizedependent sperm displacement. Evolution 54: 924-935.

Parker GA, Ball MA, Stockley P, Gage MJG. 1996. Sperm competition games: Individual assessment of sperm competition intensity by group spawners. Proc $R$ Soc Lond B 263: 1291-1297.

Perry JC, Sirot L, Wigby S. 2013. The seminal symphony: How to compose an ejaculate. Trends Ecol Evol 28: 414422.

Pitnick S, Hosken DJ, Birkhead TR. 2009. Sperm morphological diversity. In Sperm biology: An evolutionary perspective (ed. Pitnick S, Hosken DJ, Birkhead TR), pp. 69-183. Academic, Orlando, FL.

Preston BT, Stockley P. 2006. The prospect of sexual competition stimulates premature and repeated ejaculation in a mammal. Curr Biol 16: R239-R241.

Ramm SA, Parker GA, Stockley P. 2005. Sperm competition and the evolution of male reproductive anatomy in rodents. Proc Biol Sci 272: 949-955.

Rice WR. 1996. Sexually antagonistic male adaptation triggered by experimental arrest of female evolution. Nature 381: $232-234$.

Rowe M, Swaddle JP, Pruett-Jones S, Webster MS. 2010. Plumage coloration, ejaculate quality and reproductive phenotype in the red-backed fairy-wren. Anim Behav 79: $1239-1246$. 
Saglam IK, Roff DA, Fairbairn DJ. 2008. Male sand crickets trade-off flight capability for reproductive potential. $J$ Evol Biol 21: 997-1004.

Sato Y, Kohama T. 2007. Post-copulatory mounting behavior of the West Indian sweetpotato weevil, Euscepes postfasciatus (Fairmaire) (Coleoptera: Curculionidae). Ethology 113: 183-189.

Schwagmeyer PL, Parker GA. 1990. Male mate choice as predicted by sperm competition in 13-lined groundsquirrels. Nature 348: 62-64.

Simmons LW. 2012. Resource allocation trade-off between sperm quality and immunity in the field cricket, Teleogryllus oceanicus. Behav Ecol 23: 168-173.

Simmons LW, Emlen DJ. 2006. Evolutionary trade-off between weapons and testes. Proc Natl Acad Sci 103: 1634616351.

Simmons LW, Craig M, Llorens T, Schinzig M, Hosken D. 1993. Bush-cricket spermatophores vary in accord with sperm competition and parental investment theory. Proc Biol Sci 251: 183-186.

Simmons LW, Alcock J, Reeder A. 2003. The role of cuticular hydrocarbons in male attraction and repulsion by female Dawson's burrowing bee, Amegilla dawsoni. Anim Behav 66: $677-685$.

Sirot LK, Wolfner MF, Wigby S. 2011. Protein-specific manipulation of ejaculate composition in response to female mating status in Drosophila melanogaster. Proc Natl Acad Sci 108: 9922-9926.

Slatyer RA, Mautz BS, Backwell PRY, Jennions MD. 2012. Estimating genetic benefits of polyandry from experimental studies: A meta-analysis. Biol Rev Camb Philos Soc 87: 1-33.

Smith HG. 1995. Experimental demonstration of a trade-off between mate attraction and paternal care. Proc Biol Sci 260: $45-51$.

Smith C, Douglas A, Jurajda P. 2002. Sexual conflict, sexual selection and sperm competition in the spawning decisions of bitterling, Rhodeus sericeus. Behav Ecol Sociobiol 51: 433-439.

Snook RR, Hosken DJ, Karr TL. 2011. The biology and evolution of polyspermy: Insights from cellular and functional studies of sperm and centrosomal behavior in the fertilized egg. Reproduction 142: 779-792.

Stockley P. 1997. Sexual conflict resulting from adaptations to sperm competition. Trends Ecol Evol 12: 154-159.

Stockley P. 2002. Sperm competition risk and male genital anatomy: Comparative evidence for reduced duration of female sexual receptivity in primates with penile spines. Evol Ecol 16: 123-137.

Stockley P, Preston BT. 2004. Sperm competition and diversity in rodent copulatory behaviour. J Evol Biol 17: 1048-1057.
Stockley P, Bottell L, Hurst JL. 2013. Wake up and smell the conflict: Odour signals in female competition. Philos Trans R Soc Lond B 368: 20130082.

Swanson WJ, Wong A, Wolfner MF, Aquadro CF. 2004. Evolutionary expressed sequence tag analysis of Drosophila female reproductive tracts identifies genes subjected to positive selection. Genetics 168: 1457-1465.

Takami Y, Sasabe M, Nagata N, Sota T. 2008. Dual function of seminal substances for mate guarding in a ground beetle. Behav Ecol 19: 1173-1178.

Timmermeyer N, Gerlach T, Guempel C, Knoche J, Pfann JF, Schliessmann D, Michiels NK. 2010. The function of copulatory plugs in Caenorhabditis remanei: Hints for female benefits. Front Zool 7: 28 .

Wedell N. 1998. Sperm protection and mate assessment in the bushcricket Coptaspis sp. 2. Anim Behav 56: 357-363.

Wedell N. 2001. Female remating in butterflies: Interaction between female genotype and nonfertile sperm. $J$ Evol Biol 14: 746-754.

Wedell N, Gage MJG, Parker GA. 2002. Sperm competition, male prudence and sperm-limited females. Trends Ecol Evol 17: 313-320.

Westneat DF. 1994. To guard mates or go forage: Conflicting demands affect the paternity of male red-winged blackbirds. Am Nat 144: 343-354.

Wigby S, Chapman T. 2004. Female resistance to male harm evolves in response to manipulation of sexual conflict. Evolution 58: 1028-1037.

Wigby S, Chapman T. 2005. Sex peptide causes mating costs in female Drosophila melanogaster. Curr Biol 15: $316-$ 321.

Wigby S, Sirot LK, Linklater JR, Buehner N, Calboli FCF, Bretman A, Wolfner MF, Chapman T. 2009. Seminal fluid protein allocation and male reproductive success. Curr Biol 19: 751-757.

Wilson CJ, Tomkins JL. 2014. Countering counteradaptations: Males hijack control of female kicking behavior. Behav Ecol doi: 10.1093/beheco/aru022.

Wingfield JC, Hegner RE, Dufty AM, Ball GF. 1990. The challenge hypothesis: Theoretical implications for patterns of testosterone secretion, mating systems, and breeding strategies. Am Nat 136: 829-846.

Wolfner MF. 2002. The gifts that keep on giving: Physiological functions and evolutionary dynamics of male seminal proteins in Drosophila. Heredity 88: 85-93.

Wysocki D, Halupka K. 2004. The frequency and timing of courtship and copulation in blackbirds, turdus merula, reflect sperm competition and sexual conflict. Behaviour 141: 501-512.

Yamane T, Miyatake T. 2012. Evolutionary correlation between male substances and female remating frequency in a seed beetle. Behav Ecol 23: 715-722. 


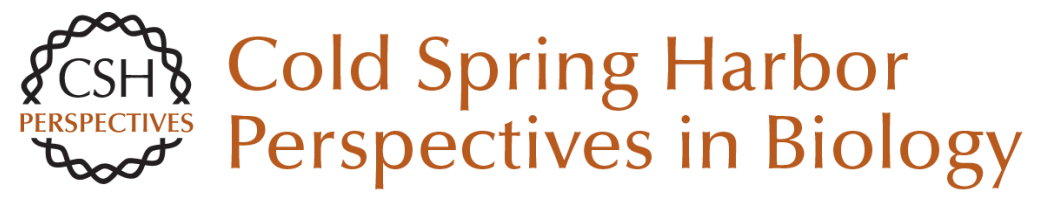

\section{Sexual Conflict and Sperm Competition}

Dominic A. Edward, Paula Stockley and David J. Hosken

Cold Spring Harb Perspect Biol 2015; doi: 10.1101/cshperspect.a017707 originally published online October 9, 2014

\section{Subject Collection The Genetics and Biology of Sexual Conflict}

Mechanisms and Evidence of Genital Coevolution: The Roles of Natural Selection, Mate Choice, and Sexual Conflict

Patricia L.R. Brennan and Richard O. Prum

The Evolution of Sexually Antagonistic Phenotypes

Jennifer C. Perry and Locke Rowe

Reproductive Parasitism: Maternally Inherited

Symbionts in a Biparental World

Gregory D.D. Hurst and Crystal L. Frost

Sex-Biased Gene Expression and Sexual Conflict throughout Development

Fiona C. Ingleby, Ilona Flis and Edward H. Morrow

Human Homosexuality: A Paradigmatic Arena for

Sexually Antagonistic Selection?

Andrea Camperio Ciani, Umberto Battaglia and Giovanni Zanzotto

Sexual Conflict Arising from Extrapair Matings in Birds

Alexis S. Chaine, Robert Montgomerie and Bruce E. Lyon

Sexual Conflict and Seminal Fluid Proteins: A

Dynamic Landscape of Sexual Interactions

Laura K. Sirot, Alex Wong, Tracey Chapman, et al.

Conflict on the Sex Chromosomes: Cause, Effect, and Complexity

Judith E. Mank, David J. Hosken and Nina Wedell
Infanticide as Sexual Conflict: Coevolution of

Male Strategies and Female Counterstrategies Ryne A. Palombit

\section{Copulatory Wounding and Traumatic} Insemination

Klaus Reinhardt, Nils Anthes and Rolanda Lange

Sexual Conflict in Hermaphrodites

Lukas Schärer, Tim Janicke and Steven A. Ramm

Sexual Conflict and Sperm Competition

Dominic A. Edward, Paula Stockley and David J. Hosken

Sexually Antagonistic Zygotic Drive: A New Form of Genetic Conflict between the Sex

Chromosomes Urban Friberg and William R. Rice

Sex Chromosome Drive

Quentin Helleu, Pierre R. Gérard and Catherine Montchamp-Moreau

Is Sexual Conflict an "Engine of Speciation"? Sergey Gavrilets

\section{Sexual Cannibalism as a Manifestation of Sexual} Conflict

Jutta M. Schneider

For additional articles in this collection, see http://cshperspectives.cshlp.org/cgi/collection/

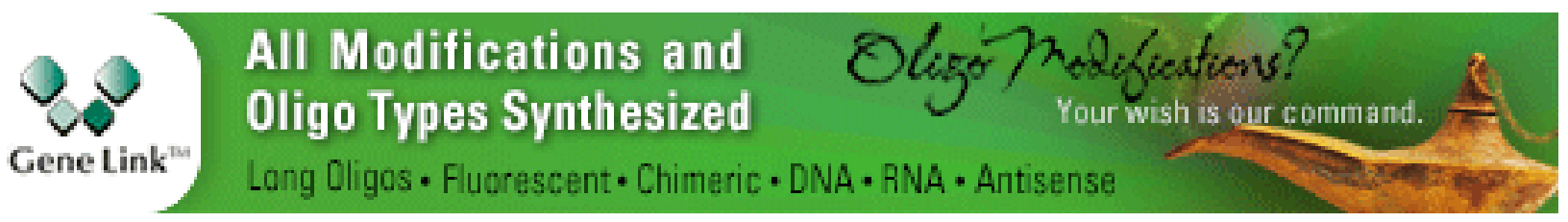


For additional articles in this collection, see http://cshperspectives.cshlp.org/cgi/collection/

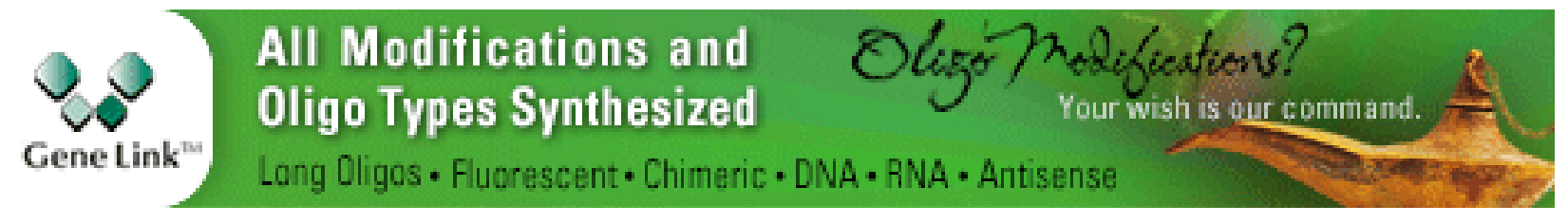

Copyright @ 2015 Cold Spring Harbor Laboratory Press; all rights reserved 